\title{
Detection of microRNA-33a-5p in serum, urine and renal tissue of patients with IgA nephropathy
}

\author{
LIHUA LIU $^{1}$, AOSONG DUAN ${ }^{2}$, QIAOYAN GUO ${ }^{1}$, GUANGDONG SUN $^{1}$, \\ WENPENG CUI ${ }^{1}$, XUEHONG LU ${ }^{1}$, HONGYU YU ${ }^{1}$ and PING LUO ${ }^{1}$ \\ ${ }^{1}$ Department of Nephrology, The Second Hospital of Jilin University, Changchun, Jilin 130041; \\ ${ }^{2}$ Department of Intensive Care Unit, The First Hospital of Jilin University, Changchun, Jilin 130021, P.R. China
}

Received January 16, 2019; Accepted June 20, 2019

DOI: $10.3892 / \mathrm{etm} .2021 .9638$

\begin{abstract}
The present study aimed to detect the levels of microRNA (miR)-33a-5p in the renal tissue, serum and urine of patients with primary $\operatorname{IgA}$ nephropathy $(\operatorname{Ig} A N)$, thereby preliminarily exploring the association between the levels of miR-33a-5p and the condition of primary IgAN to provide evidence for the expression of miR-33a-5p in the serum and urine of IgAN patients as a clinical marker. Reverse-transcription quantitative PCR was performed to evaluate the level of miR-33a-5p in IgAN patients according to severity and pathological classification. The results suggested that the levels of miR-33a-5p in the serum, urine and kidney tissues of patients with IgAN were lower than those of the control tissues obtained from cancer patients $(0.28 \pm 0.25$ vs. $1.00 \pm 0.45, \mathrm{P}<0.05 ; 0.34 \pm 0.28$ vs. $1.00 \pm 0.53, \mathrm{P}<0.05 ; 0.47 \pm 0.27$ vs. $1.00 \pm 0.38, \mathrm{P}<0.05$, respectively). Receiver operating characteristic curve analysis suggested that the serum and urine levels of miR-33a-5p may be used as a marker to differentiate renal injury in IgAN patients from healthy individuals. At the same time, according to the estimated glomerular filtration rate (eGFR) and Lee classification of nephropathy, it was determined that with the progression of renal failure and the increase of the pathological grade of kidney tissue, the relative level of miR-33a-5p in kidney tissue also decreased (eGFR $<50 \mathrm{ml} / \mathrm{min}$ vs. eGFR $\geq 50 \mathrm{ml} / \mathrm{min} / 1.73 \mathrm{~m}^{2}$ group: $0.38 \pm 0.27$ vs. $1.00 \pm 0.34, \mathrm{P}<0.001$; Lee grade $\leq 3$ group vs. Lee grade $>3$ : $1.00 \pm 0.48$ vs. $0.38 \pm 0.45, \mathrm{P}<0.05)$. This result suggested that the levels of miR-33a-5p in serum, urine and kidney tissues decreased with the severity of renal injury and the progression of renal failure in patients with IgAN. Hence, miR-33a-5p detected in the serum and urine may be used as a non-invasive
\end{abstract}

Correspondence to: Dr Ping Luo, Department of Nephrology, The Second Hospital of Jilin University, 218 Ziqiang Street, Changchun, Jilin 130041, P.R. China

E-mail: ag201916@sina.com

Key words: IgA nephropathy, microRNA-33a-5p, serum, urine, renal tissue biomarker to reflect the progression of renal injury and renal failure in patients with IgAN.

\section{Introduction}

$\operatorname{Ig}$ A nephropathy (IgAN) is the most common type of primary glomerulonephritis worldwide. In China, it accounts for $30-40 \%$ of primary glomerulonephritis cases (1). At $10-20$ years after diagnosis, $20-40 \%$ of IgAN patients progress to end-stage renal disease (1). IgAN requires to be diagnosed by renal biopsy. However, as renal biopsy is traumatic and patients frequently refuse to undergo the procedure, it cannot be used as a routine means to detect the disease. In the clinic, urinary microalbumin, 24-h urinary protein, serum creatinine and glomerular filtration rate (GFR) are commonly used to evaluate the condition and prognosis of $\operatorname{IgAN}$. However, these indicators have numerous influencing factors, and their sensitivity and specificity are poor.

It has been indicated that certain microRNAs (miRNAs/miRs) have important roles in the pathogenesis, inflammatory response, renal fibrosis and prognosis of IgAN $(2,3)$. miRNAs are expressed not only in tissues and cells but also in plasma and urine (3). Studies have identified that miRNAs are stable in peracid or alkali environments, and may persist after long storage at room temperature, multiple thaws and exposure to certain active RNAses $(2,4)$. In addition, the collection of plasma and urine samples is easy and non-invasive, and is more acceptable as opposed to biopsy for patients (5). Therefore, plasma and urine miRNAs associated with the pathophysiological changes of IgAN may be a novel non-invasive marker for IgAN (6). However, research on miRNAs in IgAN is still in its infancy, and the correlation between the expression of certain miRNAs and the pathological changes and clinical manifestations of IgAN patients requires further study $(7,8)$. It has been indicated that miRNAs in urinary sediment are easy to obtain and may be potential non-invasive biomarkers for IgAN (9). For instance, urinary miR-3613-3p was reported to be downregulated in IgAN patients and correlated with the severity of the disease (8). Hence, exploration of the association between miRNAs and IgAN may provide approaches for the early diagnosis of IgAN.

A recent study has indicated a reduction of miR-33-5p levels in the urine of $\mathrm{db} / \mathrm{db}$ mice and type 2 diabetes mellitus 
patients, and miR-33-5p levels were negatively correlated with albuminuria (10). In the pathogenesis of HIV-associated nephropathy (HIVAN), miR-33-5p was reported to be decreased in subjects with HIV-1 infections. However, whether miR-33-5p is involved in the progression of $\operatorname{IgAN}$ has remained elusive.

The present study aimed to detect the expression of miR-33-5p in the renal tissue, serum and urine of patients with primary $\operatorname{Ig} \mathrm{AN}$, thereby preliminarily exploring the association between the expression of miR-33-5p and the condition of primary $\operatorname{IgAN}$ to test the possibility of utilizing the expression of miR-33-5p in the serum and urine of IgAN patients as biomarkers. The present study provides a reference and a novel idea for the utilization of these non-invasive diagnostic markers in the diagnosis of $\operatorname{Ig} \mathrm{AN}$.

\section{Materials and methods}

Patients and samples. A total of 100 patients diagnosed with IgAN by renal biopsy and clinical and laboratory examinations at the Department of Nephrology, the Second Hospital of Jilin University (Changchun, China) between December 2016 and June 2017 were enrolled in the study as the IgAN group. This group comprised 59 males and 41 females, with an average age of $35.55 \pm 9.66$ years. On the morning of renal biopsy, morning urine and fasting venous blood samples were simultaneously collected, of which 20 patients were enrolled in renal biopsy. The kidney tissue of these patients was collected as control specimens for patients with $\operatorname{Ig} \mathrm{AN}$. The patients with IgAN were divided into five subgroups according to the Lee classification (11): 24 patients with grade I, 24 patients with grade II, 18 patients with grade III, 17 patients with grade IV and 17 patients with grade V. In the same time window, kidney tissue samples were collected from 20 patients receiving nephrectomy due to upper-tract urothelial carcinoma, including 12 males and 8 females, with an average age of $43.2 \pm 7.5$ years, at the Second Hospital of Jilin University (Changchun, China) (12). Kidney tissues that were far away (minimum distance, $2 \mathrm{~cm}$ ) from the tumor tissues and were of normal pathology were selected. Informed consent was obtained from all participants.

The inclusion criteria were as follows: i) Patients agreed to provide renal puncture tissue, plasma and urine samples to be analyzed in the present study and provided written informed consent; ii) age $\geq 18$ years; iii) no previous treatment with glucocorticoids, immunosuppressive agents or kidney transplantation; and iv) kidney pathology indicated that the deposition of IgA-based IgGs or complements in the mesangial region was strongly positive for IgA under light microscopy (XDS-500D; Shanghai Caikon Optical Instrument Co., Ltd.).

The exclusion criteria were as follows: i) Secondary IgAN caused by allergic purpura, systemic lupus erythematosus, hepatitis B virus infection, cirrhosis, tumors, or inflammatory bowel disease; ii) other kidney diseases, including membranous nephropathy, hypertensive nephropathy and diabetic nephropathy, minimal-change disease diagnosed under electronic microscopy (JEM-1011; JEOL); iii) systemic diseases including diabetes mellitus and connective tissue disease; iv) glomerulus number in renal
Table I. Clinical data of patients with IgA nephropathy.

\begin{tabular}{lc}
\hline Clinical indicator & Value \\
\hline Sex (male/female, $\%)$ & $59 / 41(59 \% / 41 \%)$ \\
Age (years) & $35.55 \pm 9.66$ \\
Course of disease (months) & $8.12 \pm 3.95$ \\
Family history & 26 \\
Scr $(\mu \mathrm{M})$ & $79.00(57.75-108.25)$ \\
eGFR $\left(\mathrm{ml} / \mathrm{min} / 1.73 \mathrm{~m}^{2}\right)$ & $90.67 \pm 42.52$ \\
BUN $(\mathrm{mM})$ & $5.05(4.06-9.43)$ \\
UA $(\mu \mathrm{M})$ & $339.24 \pm 109.71$ \\
CYS $(\mathrm{mg} / \mathrm{l})$ & $0.98(0.76-1.69)$ \\
TP $(\mathrm{g} / \mathrm{l})$ & $55.45(43.65-63.48)$ \\
ALB $(\mathrm{g} / \mathrm{l})$ & $32.59 \pm 9.61$ \\
GLOB $(\mathrm{g} / \mathrm{l})$ & $20.95(18.75-26.43)$ \\
T-CHO $(\mathrm{mM})$ & $6.23 \pm 3.17$ \\
TG $(\mathrm{mM})$ & $1.94 \pm 1.29$ \\
HDL $(\mathrm{mM})$ & $1.36 \pm 0.49$ \\
LDL $(\mathrm{mM})$ & $4.27 \pm 2.67$ \\
HB $(\mathrm{g} / \mathrm{l})$ & $131.26 \pm 23.28$ \\
U-Prot $(\mathrm{g} / 24$ h) & $2.53(0.94-4.25)$ \\
Urine RBC count $(/ \mu \mathrm{l})$ & $38.79(12.00-393.50)$ \\
C3 $(\mathrm{g} / \mathrm{l})$ & $1.08 \pm 0.21$ \\
C4 $(\mathrm{g} / \mathrm{l})$ & $0.22(0.18-0.26)$ \\
Systolic blood pressure $(\mathrm{mmHg})$ & $126.50(120.00-144.00)$ \\
Diastolic blood pressure $(\mathrm{mmHg})$ & $82.00(73.00-100.00)$ \\
\hline & \\
\hline
\end{tabular}

Values are expressed as the mean \pm standard deviation, median (range) or $\mathrm{n}$. Scr, serum creatinine; eGFR, estimated glomerular filtration rate; BUN, serum urea nitrogen; UA, serum uric acid; CYS, serum cystatin; TP, total blood protein; ALB, serum albumin; GLOB, hemoglobin; T-CHO, serum total cholesterol; TG, serum triglyceride; HDL, serum high-density lipoprotein; LDL, serum low-density lipoprotein; HB, hemoglobin; U-Prot, 24-h urine protein; C3, serum complement $\mathrm{C} 3$; $\mathrm{C} 4$, serum complement $\mathrm{C} 4$; RBC, red blood cell.

biopsy tissues $<10$; v) urinary tract infections; and vi) cases of lactation and pregnancy.

The clinical data of the cohort are listed in Table I. The above-mentioned clinical indicators were determined prior to the renal biopsy in patients with IgAN after admission. The estimated GFR (eGFR) was calculated according to the Chronic Kidney Disease Epidemiology group equation for Chinese individuals (13).

Age- and gender-matched healthy controls were selected at the Second Hospital of Jilin University during the same time window, and their blood and urine were collected. This healthy control group $(n=50)$ included 27 males and 23 females with an average age of $35.07 \pm 6.13$ years.

RNA extraction. Total RNA was isolated from the serum samples ( $5 \mathrm{ml}$, collected in tubes containing EDTA) or urine or tissues using RNAVzol LS or RNAVzol (Vigorous Biotechnology Beijing Co., Ltd.) according to the manufacturer's protocol. The concentration and purity of the RNA samples were determined by measuring the optical density ratio at $260 / 280 \mathrm{~nm}$. 

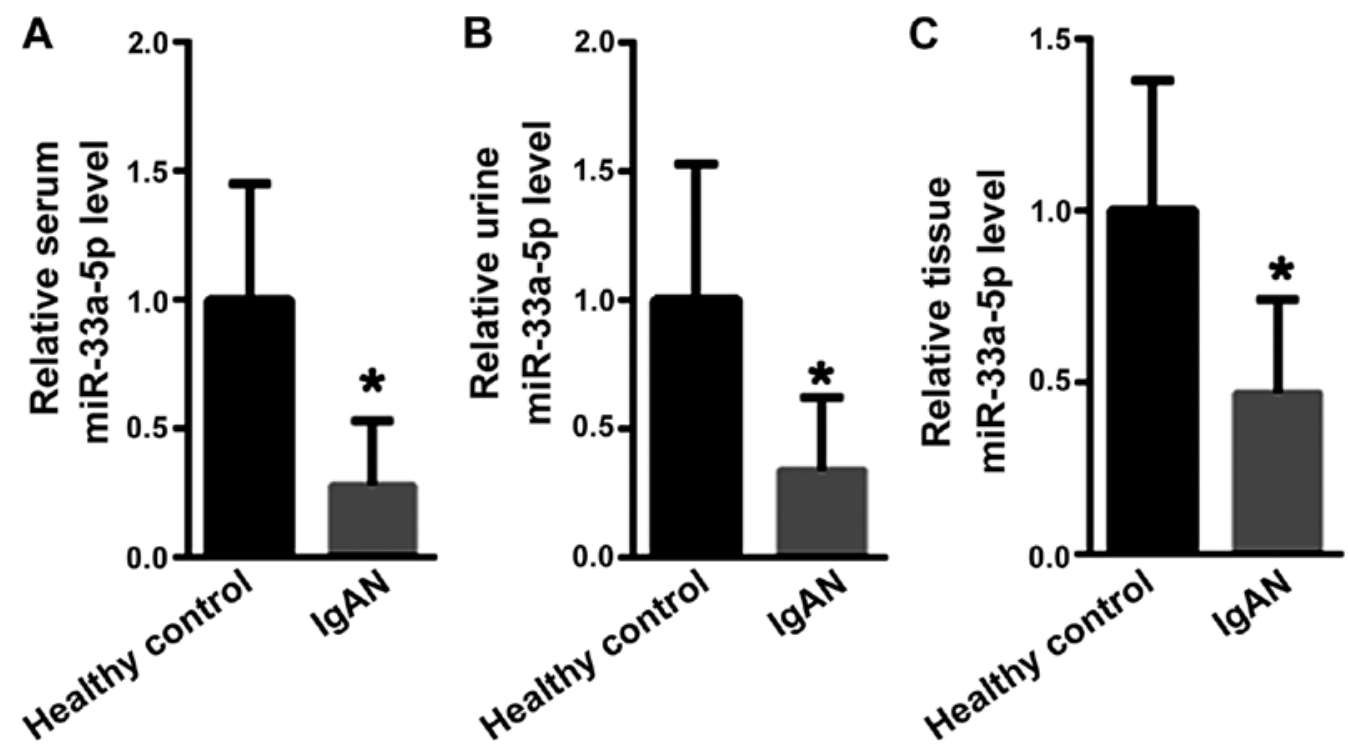

Figure 1. Reverse-transcription quantitative PCR analysis was performed to explore the expression of miR-33a-5p in serum, urine and kidney tissues. (A and B) The levels of miR-33a-5p in (A) serum and (B) urine of the IgAN group were significantly lower than those of the healthy control group. (C) The level of miR-33a-5p in kidney tissues of the IgAN group was reduced compared with that in patients who received biopsy due to renal cancer. ${ }^{*} \mathrm{P}<0.05$ vs. healthy controls. IgAN, IgA nephropathy; miR, microRNA.

Reverse transcription-quantitative $(R T-q) P C R$. A total of $1 \mu \mathrm{g}$ of RNA was reverse transcribed using Moloney Murine Leukemia Virus RT enzyme (Applied Biosystems; Thermo Fisher Scientific, Inc.) with specific primers. The protocol used for RT as follows: $72^{\circ} \mathrm{C}$ for $10 \mathrm{~min}, 42^{\circ} \mathrm{C}$ for $60 \mathrm{~min}, 72^{\circ} \mathrm{C}$ for $5 \mathrm{~min}$ and $95^{\circ} \mathrm{C}$ for $2 \mathrm{~min}$. To quantify the relative mRNA levels, qPCR was performed using SYBR Green SuperMix (Bio-Rad Laboratories, Inc.) in an iCycleriQ real-time PCR detection system. The PCR amplifications were performed in a $10-\mu 1$ reaction system containing $5 \mu \mathrm{l}$ SYBR Green SuperMix, $0.4 \mu \mathrm{l}$ forward primer, $0.4 \mu \mathrm{l}$ reverse primer, $2.2 \mu \mathrm{l}$ double-distilled $\mathrm{H}_{2} \mathrm{O}$ and $2 \mu \mathrm{l}$ template complementary DNA. Thermocycling conditions were as follows: $95^{\circ} \mathrm{C}$ for $10 \mathrm{~min}$, followed by 40 cycles of $95^{\circ} \mathrm{C}$ for $15 \mathrm{sec}$ and $60^{\circ} \mathrm{C}$ for $1 \mathrm{~min}$. Relative mRNA expression was normalized to U6 using the $2^{-\Delta \Delta \mathrm{Cq}}$ method (14). Primer sequences were as follows: miR-33-5p-RT, 5'-GTC GTATCCAGTGCAGGGTCCGAGGTATTCGCACTGGAT ACGACTGCAAT-3'; U6-RT, 5'-GTCGTATCCAGTGCA GGGTCCGAGGTATTCGCACTGGATACGACAAAATG-3'; miR-33-5p, forward 5'-GCGCGUGCAUUGUAGUUGC-3'; U6, forward 5'-GCGCGTCGTGAAGCGTTC-3'; and universal reverse primer, 5'-GTGCAGGGTCCGAGGT-3'.

Statistical analysis. Values are expressed as the mean \pm standard deviation. Two-tailed unpaired Student's t-tests were used for comparisons between two groups using SPSS version 13.0 (SPSS, Inc.). Receiver operating characteristic (ROC) curves were used to assess the diagnostic accuracy of miR-33-5p as a biomarker, and the area under the ROC curve (AUC) was determined with SPSS version 20.0 (IBM Corp). $\mathrm{P}<0.05$ was considered to indicate a statistically significant difference.

\section{Results}

Expression of miR-33a-5p in blood, urine and kidney tissues. RT-qPCR indicated that the relative levels of miR-33a-5p in the serum and urine of the IgAN group $(n=100)$ were significantly lower than those in the healthy control group $(n=50)$ $(0.28 \pm 0.25$ vs. $1.00 \pm 0.45, \mathrm{P}<0.05 ; 0.34 \pm 0.28$ vs. $1.00 \pm 0.53$, $\mathrm{P}<0.05$; Fig. $1 \mathrm{~A}$ and $\mathrm{B}$, respectively). Furthermore, the relative expression level of miR-33a-5p was decreased in kidney tissues of the IgAN group compared with those of the patients who received biopsy due to renal cancer $(n=20 ; 0.47 \pm 0.27$ vs. $1.00 \pm 0.38, \mathrm{P}<0.05$; Fig. 1C).

Blood and urine miR-33a-5p levels may differentiate IgAN patients from healthy controls. When the cutoff value was 0.13 , the AUC of serum miR-33a-5p in IgAN patients was $0.912(95 \% \mathrm{CI}=0.819-1.000, \mathrm{P}<0.001)$, with a sensitivity of $88.6 \%$ and specificity of $97.4 \%$. The results indicated that serum miR-33a-5p could distinguish IgAN patients from normal controls (Fig. 2A). Furthermore, when the cutoff value was 0.18 , the AUC of urine miR-33a-5p in $\operatorname{Ig} \mathrm{AN}$ patients $(\mathrm{n}=100)$ was $0.942(95 \% \mathrm{CI}=0.858-1.000, \mathrm{P}<0.001)$, with a sensitivity of $87.8 \%$ and specificity of $98.7 \%$ (Fig. 2B). These results indicated that serum as well as urine miR-33a-5p may be used as diagnostic markers for IgAN patients. The aforementioned results indicated that serum and tissue miR-33a-5p could distinguish patients with IgAN from control individuals.

miR-33a-5p is decreased along with impaired renal function. The IgAN patients were divided into two groups according to the eGFR, namely $<50 \mathrm{ml} / \mathrm{min} / 1.73 \mathrm{~m}^{2}$ and $\geq 50 \mathrm{ml} / \mathrm{min} / 1.73 \mathrm{~m}^{2}$ (52 vs. 48 cases). The relative levels of miR-33a-5p were decreased in serum, urine and kidney tissues in the eGFR $<50 \mathrm{ml} / \mathrm{min} / 1.73 \mathrm{~m}^{2}$ group compared with those in the eGFR $\geq 50 \mathrm{ml} / \mathrm{min} / 1.73 \mathrm{~m}^{2}$ group $(0.45 \pm 0.43$ vs. $1.00 \pm 0.57, \mathrm{P}<0.05$; $0.52 \pm 0.37$ vs. $1.00 \pm 0.56, \mathrm{P}<0.05$; and $0.38 \pm 0.27$ vs. $1.00 \pm 0.34$, $\mathrm{P}<0.001$, respectively; Fig. 3).

Serum miR-33a-5p is reduced along with enhanced urinary protein level. The IgAN group was divided into a $\leq 1.5 \mathrm{~g} / 24 \mathrm{~h}$ 

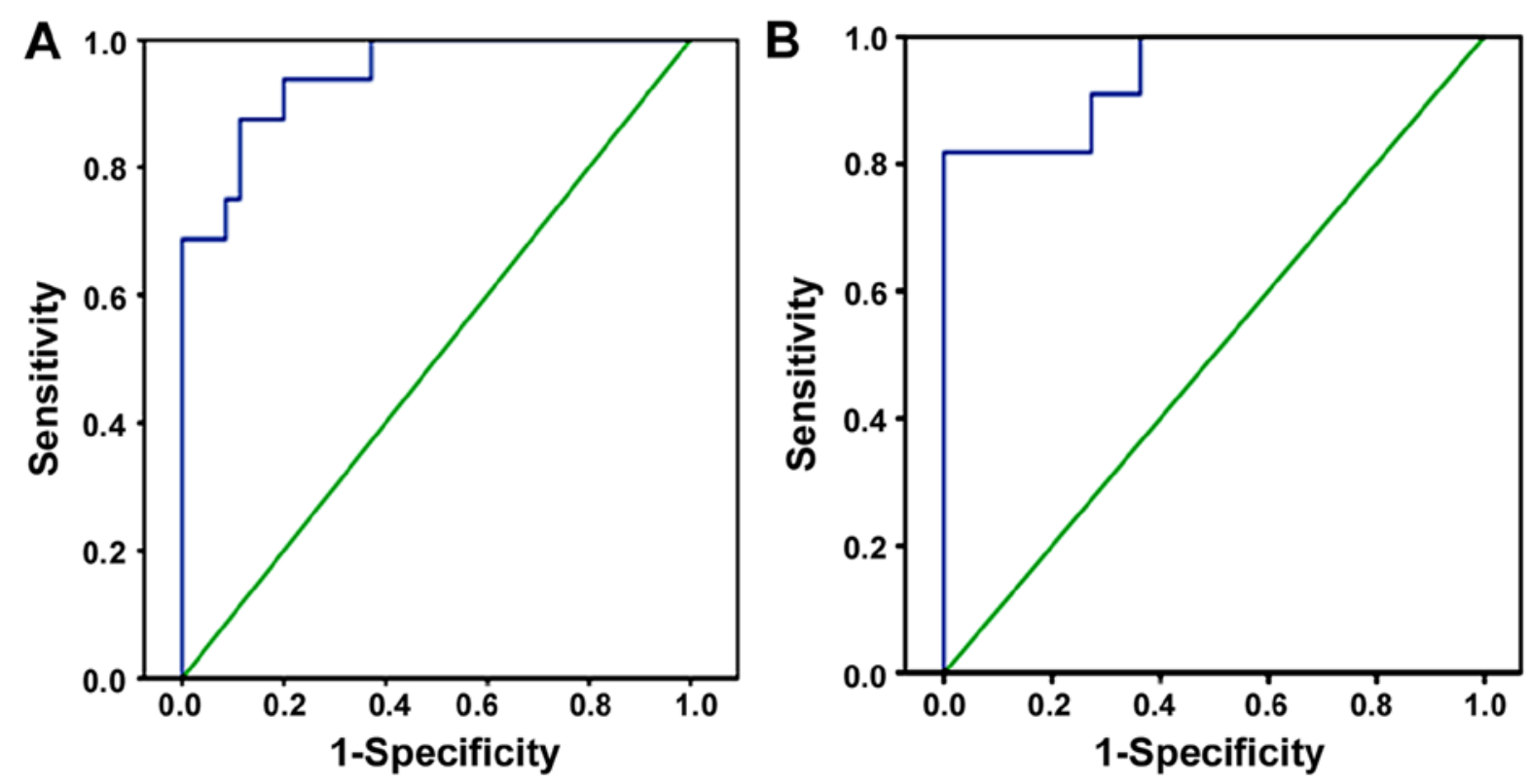

Figure 2. Receiver operating characteristic curve analysis was performed to evaluate the diagnostic value of serum and urine miR-33a-5p in IgAN patients. (A) When the cutoff value was 0.13 , the AUC of serum miR-33a-5p in IgAN patients was 0.830 with a sensitivity of $68.6 \%$ and specificity of $89.3 \%$. (B) When the cutoff value was 0.18 , the AUC of urine miR-33a-5p in IgAN patients was 0.790 , with a sensitivity of $87.8 \%$ and specificity of $98.7 \%$. IgAN, IgA nephropathy; miR, microRNA; AUC, area under the curve.

A

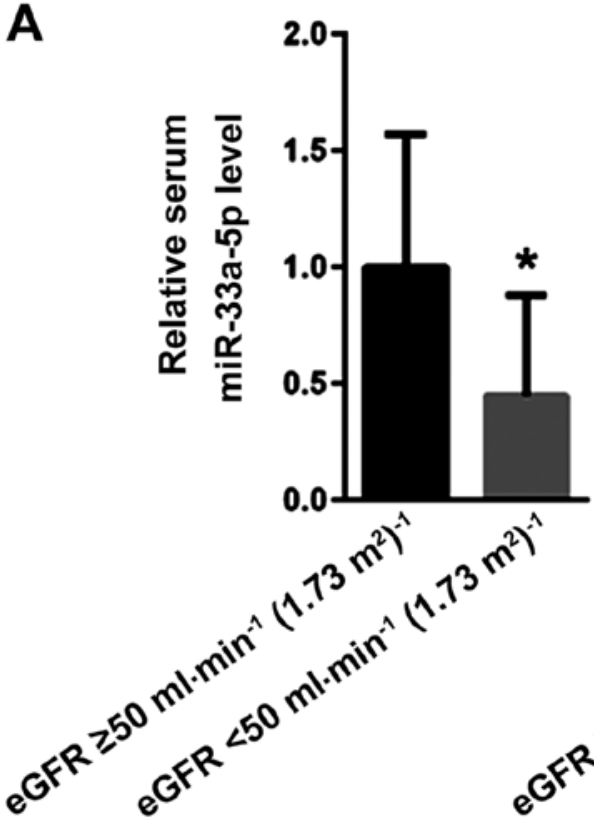

B

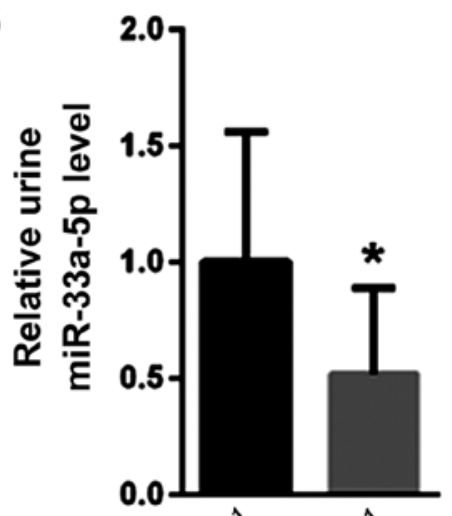

C

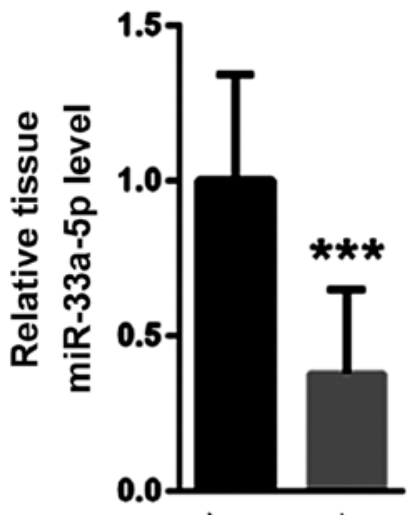

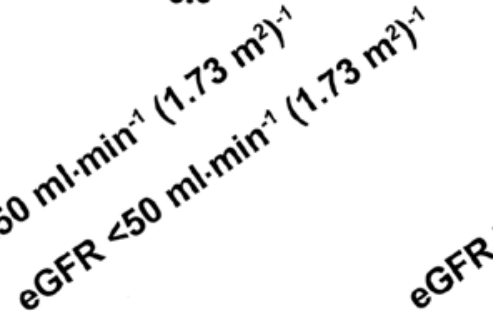

Figure 3. Reverse-transcription quantitative PCR analysis was performed to analyze the level of miR-33a-5p in association with renal function. Compared with those in the eGFR $\geq 50 \mathrm{ml} / \mathrm{min} / 1.73 \mathrm{~m}^{2}$ group, the levels of miR-33a-5p were decreased in (A) the serum, (B) urine and (C) kidney tissues of the eGFR $<50 \mathrm{ml} / \mathrm{min} / 1.73 \mathrm{~m}^{2}$ group. ${ }^{*} \mathrm{P}<0.05,{ }^{* * * *} \mathrm{P}<0.001 \mathrm{vs}$. eGFR $\geq 50 \mathrm{ml} / \mathrm{min} / 1.73$ group. eGFR, estimated glomerular filtration rate; miR, microRNA.

group and a $>1.5 \mathrm{~g} / 24 \mathrm{~h}$ group according to the amount of urinary protein (46 vs. 54 cases). The levels of miR-33a-5p in serum, urine and kidney tissues were decreased in the group with a urine protein content of $>1.5 \mathrm{~g} / 24 \mathrm{~h}$ compared with those in the group with a urine protein content of $\leq 1.5 \mathrm{~g} / 24 \mathrm{~h}$ $(0.45 \pm 0.39$ vs. $1.00 \pm 0.53, \mathrm{P}<0.05 ; 0.55 \pm 0.42$ vs. $1.00 \pm 0.61$, $\mathrm{P}>0.05 ; 0.58 \pm 0.49$ vs. $1.00 \pm 0.74, \mathrm{P}>0.05$; respectively; Fig. 4). The level of miR-33a-5p in serum was significantly decreased $(\mathrm{P}<0.05)$, but there was no significant difference in the urine and kidney tissue levels of miR-33a-5p between the two groups.

miR-33a-5p is decreased with the severity of nephropathy. IgAN patients were divided according to Lee's classification of nephropathy into grade $\leq 3$ and $>3$ groups (38 vs. 62 cases). Compared with those in the Lee grade $\leq 3$ group, the miR-33a-5p levels in the serum $(1.00 \pm 0.45$ vs. $0.58 \pm 0.37, \mathrm{P}<0.05)$, urine $(1.00 \pm 0.48$ vs. $0.49 \pm 0.31, \mathrm{P}<0.05)$ 

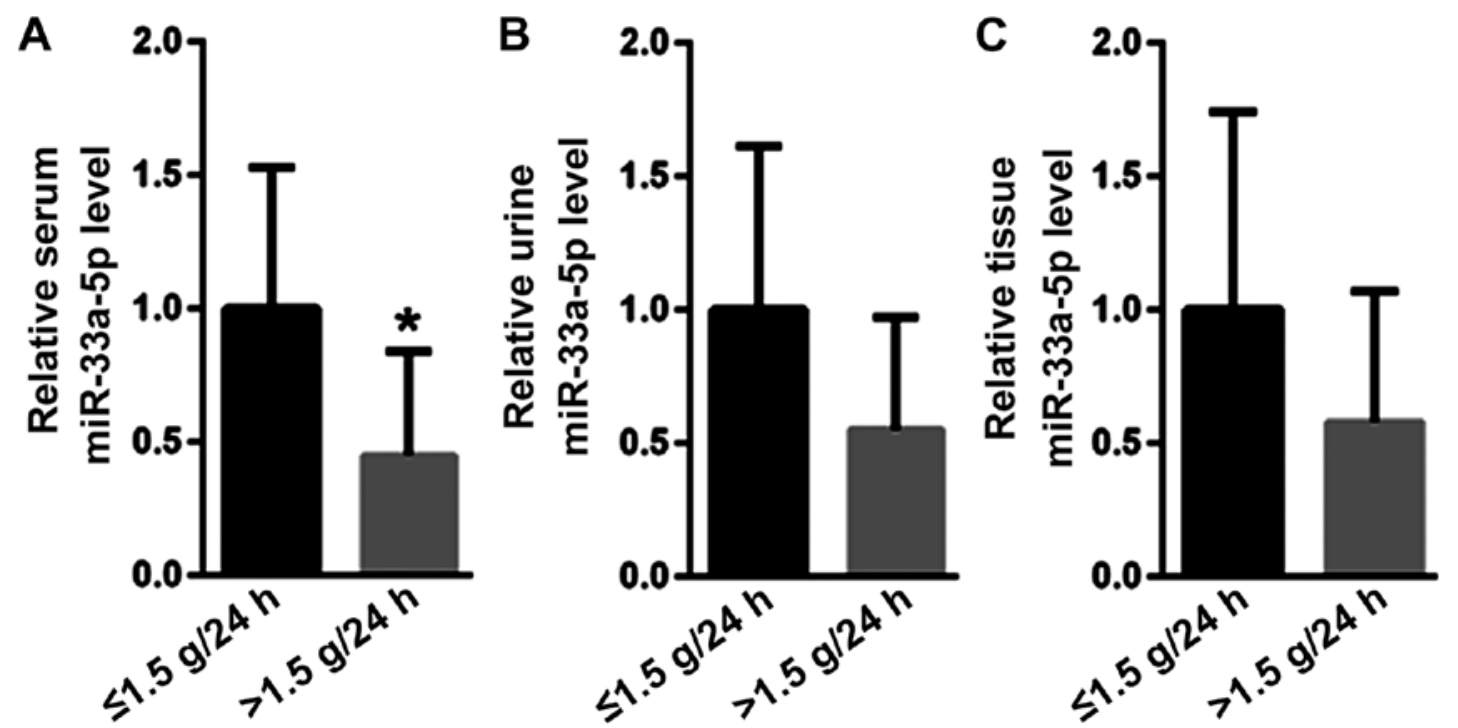

Figure 4. Reverse-transcription quantitative PCR analysis was performed to evaluate the expression of miR-33a-5p in association with urine protein content. While the group whose urine protein content was $\leq 1.5 \mathrm{~g} / 24 \mathrm{~h}$ was set as 1 , the levels of miR-33a-5p in serum (A; $0.45 \pm 0.29)$ urine (B; $0.55 \pm 0.42)$ and kidney tissues $(\mathrm{C} ; 0.58 \pm 0.39)$ were decreased in the group whose urine protein content was $>1.5 \mathrm{~g} / 24 \mathrm{~h}$. Significance was only established in serum. ${ }^{*} \mathrm{P}<0.05 \mathrm{vs}$. $\leq 1.5 \mathrm{~g} / 24 \mathrm{~h}$ group. miR, microRNA.
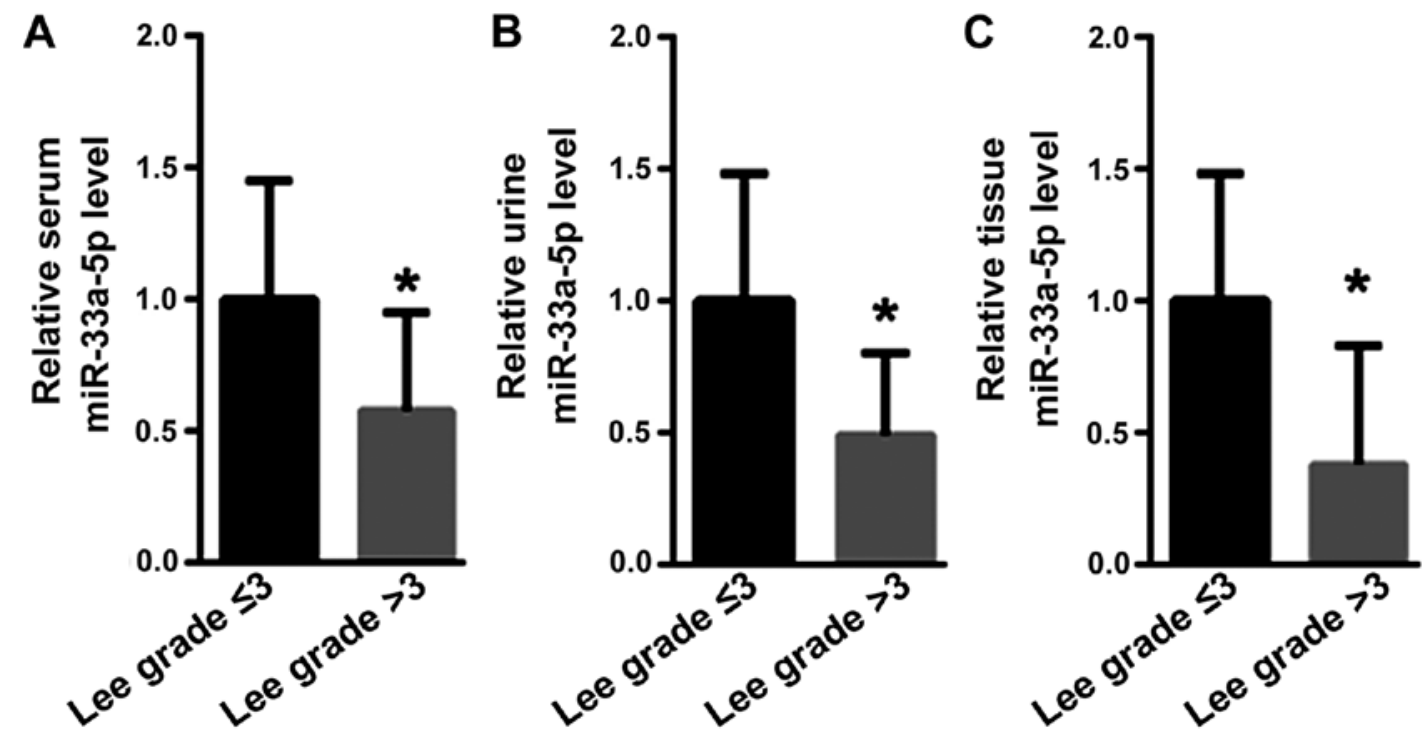

Figure 5. Reverse-transcription quantitative PCR was performed to explore the level of miR-33a-5p in association with the pathological grading of nephropathy. Compared with those in the Lee grade $\leq 3$ group, the levels of miR-33a-5p in (A) serum, (B) urine and (C) renal tissue of IgAN patients in the Lee grade $>3$ group tended to decrease. ${ }^{*} \mathrm{P}<0.05$ vs. Lee grade $\leq 3$ group. miR, microRNA.

and renal tissue $(1.00 \pm 0.48$ vs. $0.38 \pm 0.25, \mathrm{P}<0.05)$ of $\operatorname{IgAN}$ patients with Lee grade $>3$ were significantly decreased (Fig. 5).

\section{Discussion}

In the present study, the expression of miR-33a-5p in the renal tissue, plasma and urine of patients with IgAN was compared withthose withrenalcancer(non-canceroustissues)and it was explored whether the miRNA expression levels were associated with the degree of pathological damage and clinical manifestations of IgAN patients, thereby evaluating the diagnostic value of miR-33a-5p to distinguish IgAN patients from non-IgAN individuals.
The results indicated that the serum, urine and kidney tissue levels of miR-33a-5p in IgAN patients were lower than those in patients with renal cancer (non-cancerous tissues). ROC analysis indicated that the level of miR-33a-5p in blood and urine may be used as a marker to differentiate IgAN patients from healthy controls. At the same time, according to the eGFR and Lee classification of nephropathy, the level of miR-33a-5p in kidney tissue decreased with the progression of renal failure and the increase of the pathological grade of kidney tissue. This result suggested that the levels of miR-33a-5p in blood, urine and kidney tissues were decreased with the severity of renal injury and the progression of renal failure in patients with IgAN. Hence, detection of miR-33a-5p in blood and urine may be used 
as a non-invasive biomarker to reflect the progression of renal injury and renal failure in $\operatorname{IgAN}$ patients. However, in the future study, this should be further confirmed via ROC analysis.

However, the reason for the change in serum miR-33a-5p levels and the underlying mechanisms remain elusive. The change may be caused by organ secretion or disease $(15,16)$. It is necessary to further study the expression level of miR-33a-5p in specific renal cell types. Similar to serum, urinary miR-33a-5p originates from extracellular bodies or microbubbles and exists in apoptotic bodies, which are highly stable $(3,17)$. miR-33a-5p in urine may be derived from glomerular ultrafiltration or secreted by renal tubules. However, due to technical limitations, there is currently no way to detect the specific source of these specific miRNAs in urine, which may come from exfoliated renal tubular epithelial cells or urinary epithelial cells (7). In addition, a future study with a large sample size is necessary to further validate the diagnostic value of miR-33a-5p. It is also important to evaluate whether miR-33a-5p acts as a marker or a mediator in the progression of IgAN. In order to determine whether miR-33a-5p is a specific diagnostic biomarker for $\operatorname{Ig} \mathrm{AN}$, further studies involving other kidney diseases for comparison, including diabetic nephropathy, HIVAN, membranous nephropathy and minimal change disease, are required.

In conclusion, in spite of the above-mentioned limitations, the present study provided novel information regarding the early diagnosis of $\operatorname{IgAN}$. These results suggest that the expression of miR-33a-5p in renal tissue, plasma and urine may be associated with the pathological changes and clinical manifestations of IgAN, providing a reference for the utilization of urine and serum miR-33a-5p as a non-invasive biomarker of IgAN.

\section{Acknowledgements}

Not applicable.

\section{Funding}

The present study was supported by a grant from the Jilin Province supporting fund of the Second Hospital of Jilin University (grant no. JLSH-20170125).

\section{Availability of data and materials}

The datasets used and/or analyzed during the current study are available from the corresponding author on reasonable request.

\section{Authors' contributions}

LL performed the experiments and analyzed the data. AD, QG and GS collected the patient samples, and analyzed and interpreted the data. WC, XL and HY performed part of the RT-qPCR experiments. PL designed the experiments, analyzed the data and gave final approval of the manuscript to be published. All authors read and approved the final manuscript.

\section{Ethics approval and consent to participate}

The present study was approved by the Research Ethics Committee of the Second Hospital of Jilin University
(Changchun, China). All patients and healthy controls provided written informed consent for participating in this study.

\section{Patient consent for publication}

Not applicable.

\section{Competing interests}

The authors declare that they have no competing interests.

\section{References}

1. Li LS and Liu ZH: Epidemiologic data of renal diseases from a single unit in China: Analysis based on 13,519 renal biopsies. Kidney Int 66: 920-923, 2004.

2. Min QH, Chen XM, Zou YQ, Zhang J,Li J, Wang Y,Li SQ, Gao QF, Sun F, Liu J, et al: Differential expression of urinary exosomal microRNAs in IgA nephropathy. J Clin Lab Anal 32, 2018.

3. Szeto CC and Li PK: MicroRNAs in IgA nephropathy. Nat Rev Nephrol 10: 249-256, 2014.

4. Bockmeyer CL, Sauberlich K, Wittig J, Eßer M, Roeder SS Vester U, Hoyer PF, Agustian PA, Zeuschner P, Amann K, et al: Comparison of different normalization strategies for the analysis of glomerular microRNAs in IgA nephropathy. Sci Rep 6: 31992, 2016.

5. Tan K, Chen J, Li W, Chen Y, Sui W, Zhang Y and Dai Y: Genome-wide analysis of microRNAs expression profiling in patients with primary IgA nephropathy. Genome 56: 161-169, 2013.

6. Wang G, Kwan BC, Lai FM, Choi PC, Chow KM, Li PK and Szeto CC: Intrarenal expression of microRNAs in patients with IgA nephropathy. Lab Invest 90: 98-103, 2010.

7. Wang G, Kwan BC, Lai FM, Chow KM, Kam-Tao Li P and Szeto CC: Expression of microRNAs in the urinary sediment of patients with IgA nephropathy. Dis Markers 28: 79-86, 2010.

8. Wang N, Bu R, Duan Z, Zhang X, Chen P, Li Z, Wu J, Cai G and Chen $X$ : Profiling and initial validation of urinary microRNAs as biomarkers in IgA nephropathy. PeerJ 3: e990, 2015.

9. Duan ZY, Cai GY, Bu R, Lu Y, Hou K and Chen XM: Selection of urinary sediment miRNAs as specific biomarkers of $\operatorname{IgA}$ nephropathy. Sci Rep 6: 23498, 2016.

10. Tsai YC, Kuo PL, Hung WW, Wu LY, Wu PH, Chang WA, Kuo MC and Hsu YL: Angpt2 induces mesangial cell apoptosis through the MicroRNA-33-5p-SOCS5 Loop in Diabetic Nephropathy. Mol Ther Nucleic Acids 13: 543-555, 2018.

11. Lee HS, Choi Y, Lee JS, Yu BH and Koh HI: Ultrastructural changes in IgA nephropathy in relation to histologic and clinical data. Kidney Int 35: 880-886, 1989.

12. Cheng K, Rai P, Plagov A, Lan X, Subrati A, Husain M, Malhotra A and Singhal PC: MicroRNAs in HIV-associated nephropathy (HIVAN). Exp Mol Pathol 94: 65-72, 2013

13. Xie P, Huang JM, Lin HY, Wu WJ and Pan LP: CDK-EPI equation may be the most proper formula based on creatinine in determining glomerular filtration rate in Chinese patients with chronic kidney disease. Int Urol Nephrol 45: 1057-1064, 2013.

14. Livak KJ and Schmittgen TD: Analysis of relative gene expression data using real-time quantitative PCR and the 2(-Delta Delta C(T)) method. Methods 25: 402-408, 2001.

15. Prabu P, Rome S, Sathishkumar C, Gastebois C, Meugnier E, Mohan V and Balasubramanyam M: MicroRNAs from urinary extracellular vesicles are non-invasive early biomarkers of diabetic nephropathy in type 2 diabetes patients with the 'Asian Indian phenotype'. Diabetes Metab 45: 276-285, 2019.

16. Selvaskandan H, Pawluczyk I and Barratt J: MicroRNAs: A new avenue to understand, investigate and treat immunoglobulin A nephropathy? Clin Kidney J 11: 29-37, 2018.

17. Srivastava SP, Koya D and Kanasaki K: MicroRNAs in kidney fibrosis and diabetic nephropathy: Roles on EMT and EndMT. Biomed Res Int 2013: 125469, 2013.

This work is licensed under a Creative Commons Attribution-NonCommercial-NoDerivatives 4.0 International (CC BY-NC-ND 4.0) License. 